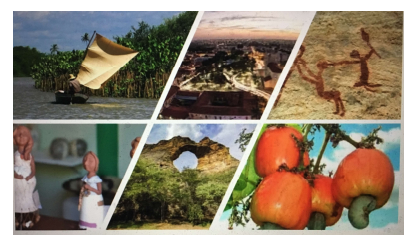

ISBN: 2675-1496 DOI: https://doi.org/10.26694/caedu.v1i2.9911

\title{
AGENOR MOREIRA SAMPAIO, O SINHOZINHO, 1891-1962: UMA VIDA PELA CAPOEIRA E PELO ESPORTE DA CIDADE DO RIO DE JANEIRO
}

\author{
Ricardo Martins Porto Lussac \\ Doutor em Educação pelo ProPEd - UERJ \\ Lattes Id: http://lattes.cnpq.br/3941119561144531
}

\begin{abstract}
Resumo
Agenor Moreira Sampaio, o Sinhozinho, 1891-1962, iniciou-se cedo nos esportes. Foi um atleta vencedor e um grande instrutor de Educação Física, formando campeões. Era Boêmio, de personalidade forte e marcante. Foi um dos pioneiros do esporte na cidade do Rio de Janeiro na primeira metade do século XX. Aprimorou-se lendo tratados estrangeiros de cultura física e mantinha estreito relacionamento com a Escola Nacional de Educação Física. Com inúmeras contribuições no ensino dos esportes, ensinou gratuitamente a Capoeira, não conseguindo comercializar este seu trabalho, apesar de obter expressivos resultados em combates de vale-tudo. A singularidade presente em sua prática, inclusive com a invenção de aparelhos, e as respectivas contribuições no ensino, resgate e difusão da Capoeira carioca, o consagraram como um dos maiores representantes na história do jogo-luta. Investigar, analisar e discutir os aspectos mais relevantes da vida esportiva e social de Agenor Moreira Sampaio, e suas contribuições para a Capoeira e para o esporte, torna relevante este trabalho por serem escassas as reflexões e pesquisas acadêmicas a respeito deste sujeito e de suas contribuições. Procurou-se por meio de um tratamento interpretativo e qualitativo estabelecer um diálogo entre as principais fontes, as obras de André Lacé Luiz Lopes e a biografia de Rudolf Hermanny, ambos alunos de Sinhô, e os autores e documentos que compuseram parte da fundamentação teórica destes autores, entre eles, precipuamente: Inezil Penna Marinho, Mário Peixoto, Ruy Castro e Sergio Pettezonni; e três importantes reportagens de jornais entre as décadas de 1930-50. Deste modo, este estudo ilumina parte de questões que envolvem o assunto ao analisar e confrontar as fontes e documentos, discutindo os processos de socialização envolvidos e as trajetórias de formação, as memórias, narrativas e experiências deste personagem da vida carioca. Deste modo, é possível inferir que esta pesquisa contribui com importantes subsídios sobre o tema.
\end{abstract}

Palavras-chave: Capoeira. Esporte. Sinhozinho. 


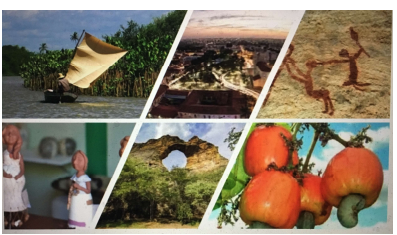

ISBN: 2675-1496 DOI: https://doi.org/10.26694/caedu.v1i2.9911

\author{
AGENOR MOREIRA SAMPAIO, THE SINHOZINHO, \\ 1891-1962: a life for capoeira and the sport of Rio de Janeiro
}

\begin{abstract}
Resume
Agenor Moreira Sampaio, Sinhozinho, 1891-1962, started early in sports. He was a winning athlete and a great instructor of Physical Education, forming champions. It was Bohemian, with a strong and striking personality. He was one of the pioneers of the sport in the city of Rio de Janeiro in the first half of the twentieth century. He improved by reading foreign treaties on physical culture and had a close relationship with the National School of Physical Education. With numerous contributions in the teaching of sports, he taught Capoeira for free, unable to commercialize his work, despite obtaining significant results in anything but fights. The uniqueness present in his practice, including the invention of gadgets, and their contributions in the teaching, rescue and diffusion of Capoeira carioca, established him as one of the greatest representatives in the history of fighting games. Investigating, analyzing and discussing the most relevant aspects of Agenor Moreira Sampaio's sporting and social life, and their contributions to Capoeira and sport, makes this work relevant because there are few reflections and academic research on this subject and his contributions. Through an interpretative and qualitative treatment, we sought to establish a dialogue between the main sources, the works of André Lacé Luiz Lopes and the biography of Rudolf Hermanny, both students of Sinhô, and the authors and documents that were part of their theoretical foundation authors, among them, mainly: Inezil Penna Marinho, Mário Peixoto, Ruy Castro and Sergio Pettezonni; and three major newspaper reports between the 1930s and 50s. Thus, this study illuminates part of the issues that involve the subject by analyzing and confronting the sources and documents, discussing the socialization processes involved and the formation trajectories, memories, narratives and experiences of this character from Rio de Janeiro life. Thus, it is possible to infer that this research contributes with important subsidies on the subject.
\end{abstract}

Key words: Capoeira. Sinhozinho. Sport.

\title{
AGENOR MOREIRA SAMPAIO, EL SINHOZINHO 1891-1962: una vida para la capoeira y el deporte de Río de Janeiro
}

\section{Resumen}

Agenor Moreira Sampaio, Sinhozinho, 1891-1962, comenzó temprano en el deporte. Fue un atleta ganador y un gran instructor de educación física, formando campeones. Era bohemio, con una personalidad fuerte y llamativa. Fue uno de los pioneros del deporte en la ciudad de Río de Janeiro en la primera mitad del siglo XX. Mejoró leyendo tratados extranjeros sobre cultura física y tuvo una estrecha relación con la Escuela Nacional de Educación Física. Con numerosas contribuciones en la enseñanza de deportes, enseñó 


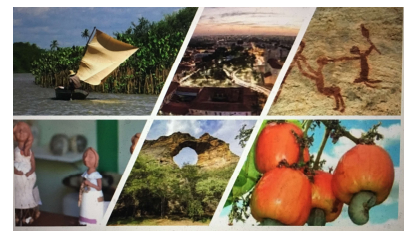

ISBN: 2675-1496 DOI: https://doi.org/10.26694/caedu.v1i2.9911

Capoeira de forma gratuita, incapaz de comercializar su trabajo, a pesar de obtener resultados significativos en todo menos en peleas. La singularidad presente en su práctica, incluida la invención de artilugios, y sus contribuciones en la enseñanza, el rescate y la difusión de Capoeira carioca, lo establecieron como uno de los más grandes representantes en la historia de los juegos de lucha. Investigar, analizar y discutir los aspectos más relevantes de la vida deportiva y social de Agenor Moreira Sampaio, y sus contribuciones a la Capoeira y el deporte, hace que este trabajo sea relevante porque hay pocas reflexiones e investigaciones académicas sobre este tema y sus contribuciones. A través de un tratamiento interpretativo y cualitativo, buscamos establecer un diálogo entre las principales fuentes, los trabajos de André Lacé Luiz Lopes y la biografía de Rudolf Hermanny, ambos estudiantes de Sinhô, y los autores y documentos que formaron parte de su fundamento teórico. autores, entre ellos, principalmente: Inezil Penna Marinho, Mário Peixoto, Ruy Castro y Sergio Pettezonni; y tres importantes informes periodísticos entre los años treinta y cincuenta. Por lo tanto, este estudio ilumina parte de los problemas que involucran al sujeto analizando y confrontando las fuentes y documentos, discutiendo los procesos de socialización involucrados y las trayectorias de formación, recuerdos, narrativas y experiencias de este personaje de la vida de Río de Janeiro. Por lo tanto, es posible inferir que esta investigación contribuye con importantes subsidios sobre el tema.

Palabras clave: Capoeira. Deporte. Sinhozinho.

\section{Agenor Moreira Sampaio: Sinhozinho ou Sinhô}

Filho do Coronel José Moreira Sampaio, que foi Intendente de Santos no ano de 1904, e da Sra. Anna Isolina Moreira Sampaio, Agenor Moreira Sampaio, posteriormente também conhecido por Sinhozinho, ou simplesmente Sinhô, nasceu em Santos, no Estado de São Paulo em 1891 e faleceu ao final do primeiro semestre de 1962, na cidade do Rio de Janeiro, R.J. (CASTRO, 2002, p. 350 a 352). 


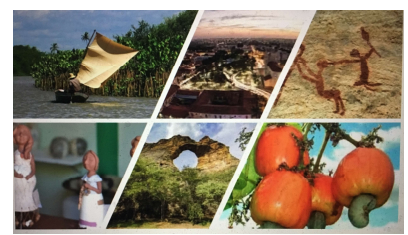

ISBN: 2675-1496 DOI: https://doi.org/10.26694/caedu.v1i2.9911

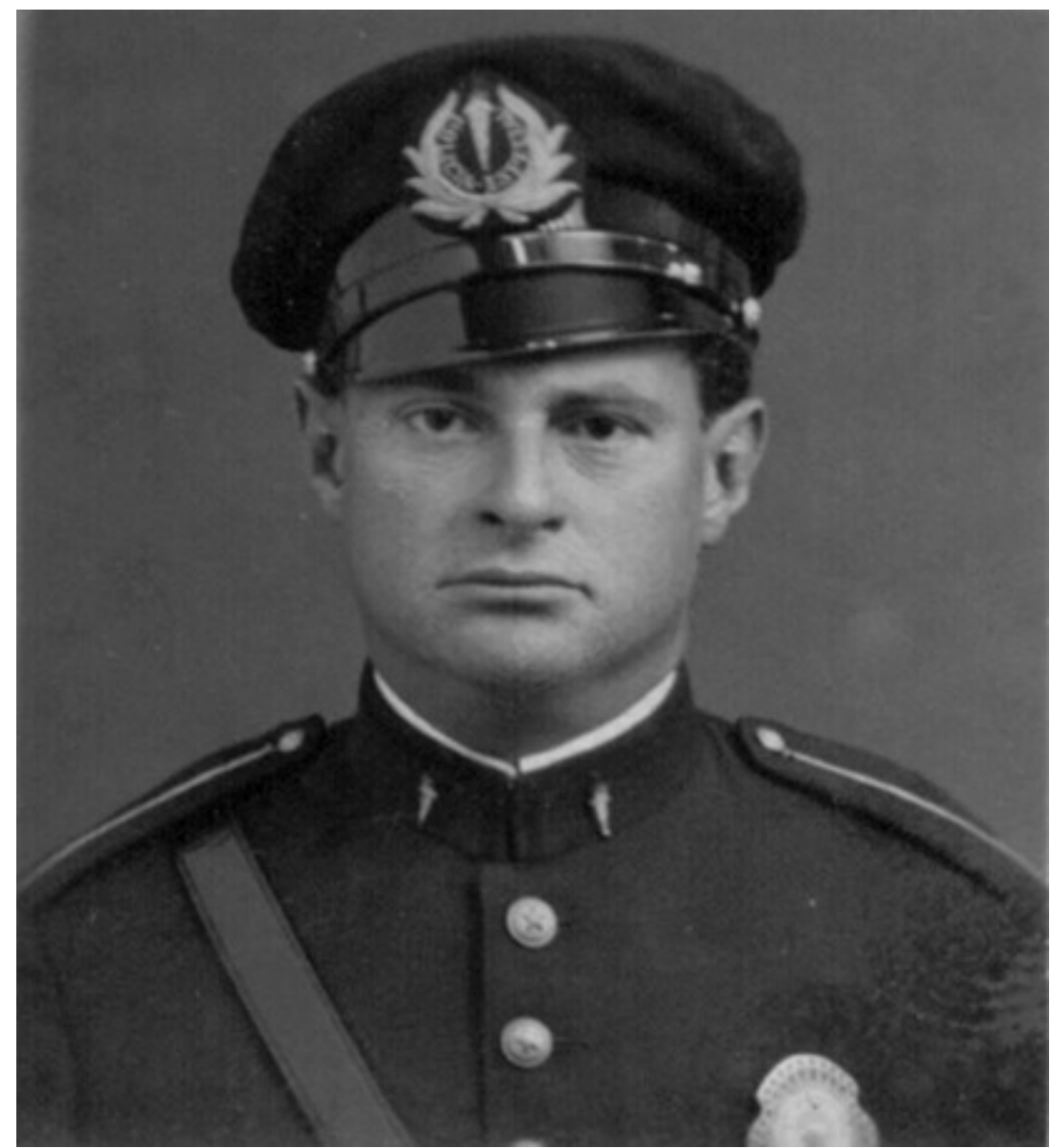

Figura 1. Agenor Moreira Sampaio, o Sinhozinho Fonte: LOPES, 2002, p. 106.

Iniciou sua vida esportiva no Clube Esperia de São Paulo entre 1904 e 1905 e, logo após, ainda no Estado de São Paulo, atuou no Clube Atlético Paulistano, o primeiro clube a ter uma piscina no Brasil, na Associação Atlética das Palmeiras, com o qual houve a fusão com o Clube Regatas São Paulo, aprendendo a ginástica com Cícero Marques e Albino Barbosa. Por último, em 1907, atuou no Clube Força e Coragem, aprendendo exercícios com o Professor Pedro Pucceti. Chegou à cidade do Rio de Janeiro aos 17 $\operatorname{anos}^{1}$, em 1908, onde foi morar no Morro de Santo Antônio, um dos mais antigos locais

\footnotetext{
${ }^{1}$ Pires (2010, p. 149) afirma que Sinhozinho havia chegado ao Rio de Janeiro com aproximadamente 30 anos de idade, portanto, por volta de 1921. Esta informação não confere com o histórico esportivo dele, pois bem antes de 1921 ele já atuava em vários clubes cariocas desde muito jovem.

Revista Caminhos da Educação: diálogos, culturas e diversidades. CAEDU/UFPI 


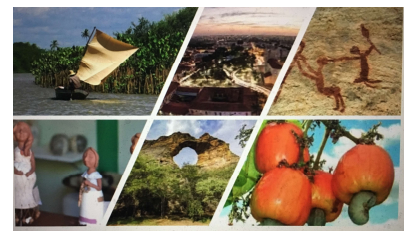

ISBN: 2675-1496 DOI: https://doi.org/10.26694/caedu.v1i2.9911

da cidade, que anos mais tarde, com as intervenções da Prefeitura Municipal, foi demolido.

Sinhozinho era um mulato baixo, atarracado e de mãos pequenas. Tímido, modesto e generoso. Tórax enorme, o pescoço, um tronco, e os braços de ferro. Mais tarde foi morar na Rua Redentor em Ipanema, onde no quintal de sua casa abriu a sua "primeira" academia, também a primeira academia de Ipanema. Tal academia seguiu para terrenos baldios na Rua Visconde de Pirajá, na Rua Conselheiro Lafayete e, ao lado de sua casa, localizada na Rua Saddock de Sá 207, também em Ipanema, a qual ficou conhecida como "Clube do Sinhozinho".

Entretanto, algumas informações e fontes divergem ou somam aos dados anteriores: segundo Peixoto (1999, p. 15, 16 e 23), a primeira academia de Sinhozinho teria sido na Rua Paul Redfern, depois seguindo para ao lado do Colégio São Paulo, na Vieira Souto; na Rua Visconde de Pirajá, ao lado do Bar Progresso, hoje Chaika; após, na Rua Barão da Torre, em frente ao Colégio Notre Dame; e finalmente, na Rua Alberto de Campos.

O mesmo autor oferece também opiniões contraditórias sobre Agenor Moreira Sampaio ao afirmar sobre o mesmo: "pertencente à família rica [...] foi malandro na Lapa" (PEIXOTO, 1999, p. 15, 16 e 23). Sobre esta afirmativa, prefiro interpretar que Peixoto se deixou levar por Sinhozinho conhecer os meandros da malandragem carioca, sem necessariamente, se tornar um tipo social negativamente visto, que vivesse de forma duvidosa no submundo da cidade. Tal malandragem, possivelmente adquirida, junto com seu conhecimento da Capoeira carioca, foi fruto de sua vivência no Morro de Santo Antônio e no cotidiano da cidade, visto o mesmo pertencer à classe trabalhadora na qual a Capoeira estava presente. Já o pertencer à uma família rica, interpreto que o autor se deixou levar pela qualidade social de seus alunos, não necessariamente pelas posses o estilo de vida de Sinhô.

\section{Aspectos esportivos}




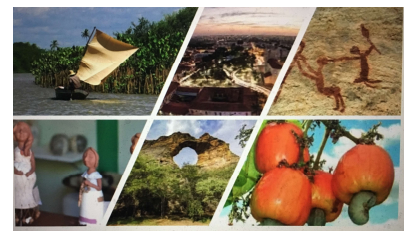

ISBN: 2675-1496 DOI: https://doi.org/10.26694/caedu.v1i2.9911

Sinhô "jogava futebol, fazia luta romana e praticava ginástica em aparelhos. Mas aqui conheceu a capoeira carioca, a violenta forma de luta dos antigos malandros da Lapa - diferente da capoeira baiana, mais coreográfica e ao som do berimbau" (CASTRO, 2002, p. 350 a 352), afirma Ruy Castro sobre a presença de Sinhozinho no Rio de Janeiro. Ainda segundo este autor, Sinhô treinou atletas de várias categorias: "quem passava por suas mãos saía campeão" (CASTRO, 2002).

Aprendeu com o aviador Edú Chaves: greco-romana, ginástica em aparelhos e box francês, a savatté. Em 1907, ele já havia vencido um torneio de greco-romana em sua categoria. Também foi campeão de queda-de-braço, modalidade na qual nunca foi vencido. Tornou-se um mestre da Capoeira carioca e aprimorou-se lendo tratados de cultura física que mandava vir da França. Agenor Moreira Sampaio foi um dos fundadores do Centro de Cultura Physica Enéas Campello, junto com João Baldi, Heraclito Max, Jayme Ferreira², e Zenha, do qual saiu em 1909 para estudar a "Educação Physica”, por meio de tratados sobre a "gymnastica corporal".

É possível elaborar uma linha do tempo, a qual possibilita um panorama melhor sobre a vida social e esportiva de Agenor Moreira Sampaio:

Em 1910 ganhou um torneio de força, no Clube de Tiro Federal, onde concorreu, inclusive, com praças do Exército. Tal competição teve como juízes o Dr. Fernando Soledade e, respectivamente, o Dr. Alvaro Zamith. Ainda em 1910, jogou no primeiro time de futebol do Sport Mangueira e praticou atletismo e competiu nas festas do Rio Cricket Athletic Assossiation de Nichteroy.

Em 1913 ficou em oitavo lugar entre quinze competidores em um campeonato de luta romana, na qual participaram grandes nomes da modalidade, como: João Baldi, José Floriano, Cesário, Petrassini, Montagna, e Negro Dick. Com 75 quilos, é possível inferir

\footnotetext{
${ }^{2} \mathrm{O}$ fato de Agenor Moreira Sampaio conhecer Jayme Ferreira demonstra existir uma rede de conhecimento pessoal entre as pessoas que praticavam e ensinavam a Capoeira de modo esportivo no Rio de Janeiro. Jayme Ferreira aparece em reportagens sobre a Capoeira, como a "Escola Typica de agressão e defeza" na Revista Noite Ilustrada, em 1931, entre outras fontes que ratificam tal rede.
} 


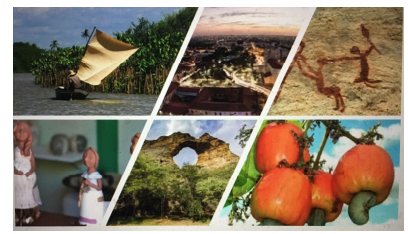

ISBN: 2675-1496 DOI: https://doi.org/10.26694/caedu.v1i2.9911

que o oitavo lugar nesta competição, que contou com adversários muito mais pesados e maiores que Sinhô - o adversário mais leve tinha 102 quilos -, foi um feito notável neste tipo de modalidade.

Em 1915 voltou ao futebol no Mangueira, e logo em 1916, ganhou o campeonato de leves, de pesos e alteres, pelo Club Gymnastico Portuguez. Em 1917 ganhou todos os campeonatos de pesos e alteres que disputou e bateu vários recordes. Mas os mesmos não foram homologados naquele ano. Participou dos Campeonatos do Rio de Janeiro nos de 1917, 1919 e 1920. A competição não foi realizada em 1918 por conta da epidemia gripe.

Em 1921 treinou gratuitamente no Sport Club Mangueira, e em 1922 participou dos Festejos do Centenário, chamado pela comissão para auxiliar nos treinamentos dos atletas que participaram do evento. Neste mesmo ano, no Clube de Regatas Flamengo, foi instrutor de luta romana e após, treinador de futebol.

Em 1923, preparou o Comandante Haroldo Borges Leitão para o Campeonato de Pesos e Alteres do Rio de Janeiro, que venceu brilhantemente. Neste mesmo ano saiu do Clube Regatas Flamengo.

Em 1925, no Clube Hellenico, treinou vários atletas, incluindo Ostinio Guimarães, que bateu o recorde carioca de arremesso de disco. A partir de 1926, atuou, inclusive como massagista, no América Futebol Clube, até, no mínimo, no ano 1931. Desde 1930 já atuava no seu Club de Gymnastica Nacional - Capoeira - localizada no segundo andar do número 133 da Rua do Rosário, com a intenção de difundir a prática ${ }^{3}$. Sinhô pretendia organizar um torneio com seus alunos da Capoeira para concretizar tal difusão e também abrir este clube em outro lugar, visto considerar que o mesmo estava em uma instalação provisória naquele momento. Em 1934 colaborou na realização de um campeonato de pesos e alteres no Clube de Regatas Flamengo, onde foi instrutor de educação física.

\footnotetext{
${ }^{3}$ É necessário lembrar que neste período a prática da Capoeira era proibida pelo Código penal de 1890, fato que perdurou até o início de 1942. Mas como eu já apresentei em outro trabalho (LUSSAC, 2004), havia uma brecha de interpretação na lei que permitia a sua prática em recintos fechados, no caso, em academias. Mas, indiscutivelmente, tal legislação facilitou que o braço opressor do Estado caísse pesadamente na prática popular da Capoeira, principalmente nos batuques e festas populares, contribuindo muito para o desaparecimento deste tipo de expressão da Capoeira.
} 


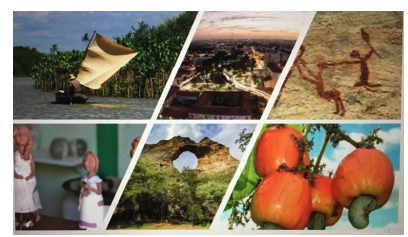

ISBN: 2675-1496 DOI: https://doi.org/10.26694/caedu.v1i2.9911

Agenor Moreira Sampaio foi preparador físico de vários clubes cariocas, entre eles: Sport Club Mangueira (1912), Ginásio Portuguêz (1916), Clube de Regatas Flamengo (1922-23 e, posteriormente, em 1934), Helênico Atlético Clube (1924), América Futebol Clube (1926), também futebol "barreira do América" próximo ao América Futebol Clube, Clube Regatas Boqueirão do Passeio (1926), Club Nacional de Gymnastica (1930) - Capoeira, e no Fluminense Futebol Clube (1936). É preciso pontuar a necessidade de maiores estudos sobre a atuação de Sinhozinho nos clubes cariocas.

\section{Sinhozinho e a capoeira}

Em 1930, Sinhozinho havia reunido seus primeiros alunos particulares, a quem ensinava Capoeira gratuitamente. De acordo com a reportagem O Destino da Capoeira, de 07 de julho de 1951, em O Globo Esportivo, sua primeira turma em 1930 possuía cinco alunos. Mas para Sinhozinho houve uma grande desilusão, já que em 1932 as aulas deixaram de ser ministradas por falta de alunos, impossibilitando os planos de difusão da prática.

Indalício Mendes, o popular Brigido, do Diário de Notícias, despendeu enormes esforços na época para a oficialização esportiva da Capoeira, o que infelizmente acabou não logrando conseguir. As manchetes das reportagens já ofereciam o tom do momento pela qual passava a Capoeira carioca: Trabalha-se no Brasil pela sobrevivência da capoeira, era uma delas, publicada em 23 de setembro de 1951, no Correio da Manhã, também no Rio de Janeiro. A principal razão para o ocorrido com Sinhô e pela situação da Capoeira carioca era por que a mesma continuava inexoravelmente marcada no tempo de modo negativo para a sociedade. 


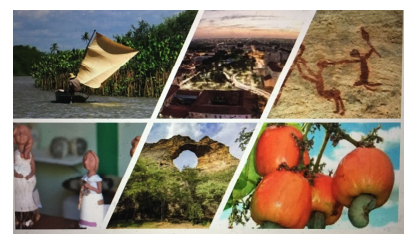

ISBN: 2675-1496 DOI: https://doi.org/10.26694/caedu.v1i2.9911

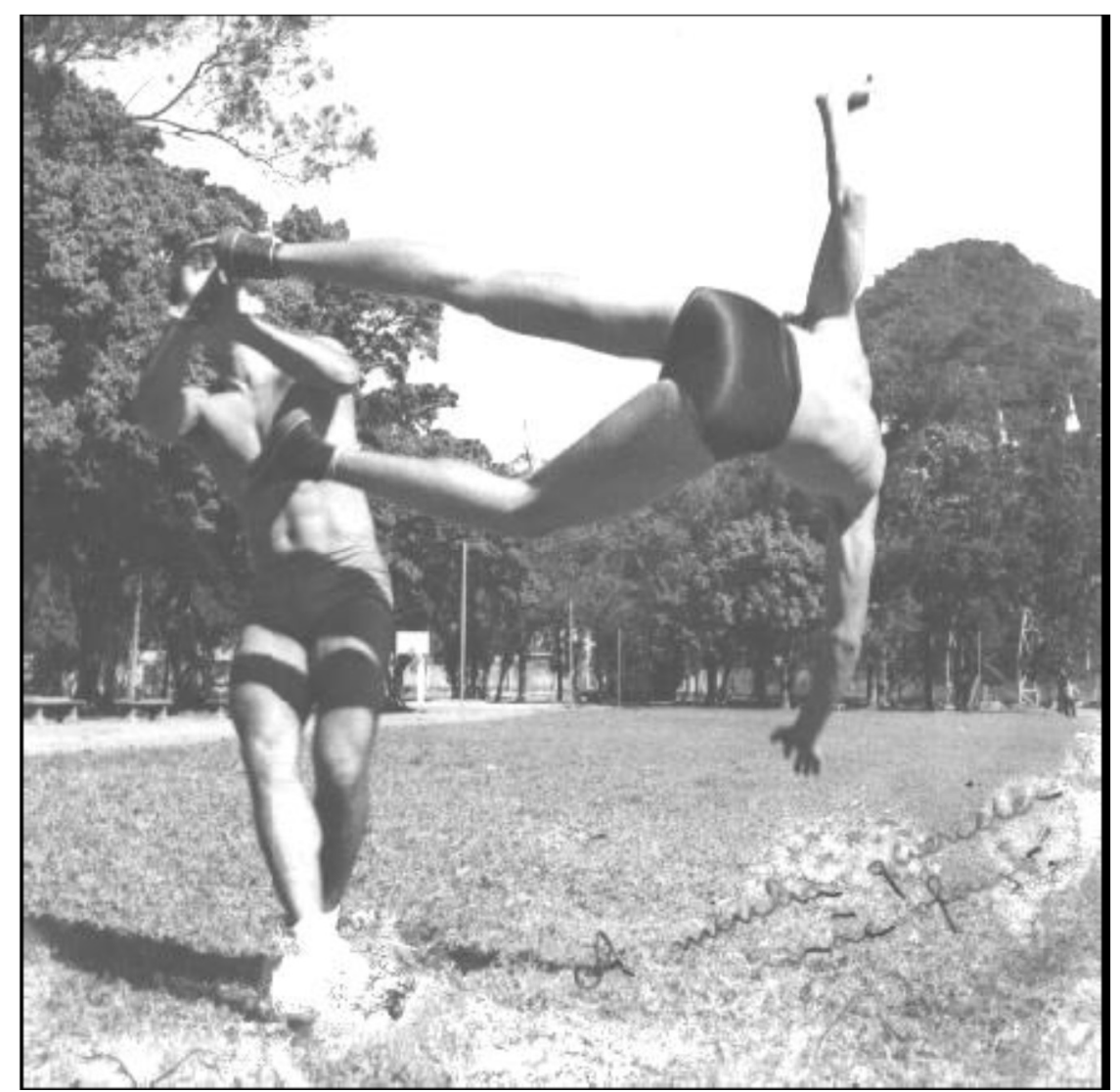

Figura 2. Alunos da Capoeira de Sinhozinho: Rudolf Hermanny aplica Quarenta e Um Dobrado em Quim - Rio de Janeiro, 1951. Fonte: LOPES, 2002, p. 140.

Em 1944, ou ainda um pouco antes deste período, Sinhozinho mantinha em Ipanema uma academia de Capoeira, "destinada aos moços grã-finos que desejam ter algum motivo para se tornar valentes" (MARINHO, 1945, p. 30). Inezil Penna Marinho e outros haviam sido alunos de Sinhô ao menos oito anos antes de 1944. Marinho cita os notáveis aparelhos, como os inventados para socos e aplicar rasteiras, que Sinhozinho inventava e o esforço para não deixar a capoeiragem morrer. Em 1951, ensinava a Capoeira no Salão da Escola Nacional de Educação Física, na Universidade do Brasil, na Praia Vermelha.

Mesmo com todas as dificuldades, é possível afirmar que ele obteve um relativo sucesso neste sentido. Sinhozinho teria se aprofundado no estudo de todos os golpes Revista Caminhos da Educação: diálogos, culturas e diversidades. CAEDU/UFPI 


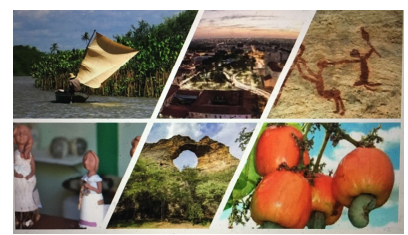

ISBN: 2675-1496 DOI: https://doi.org/10.26694/caedu.v1i2.9911

utilizados pelos precursores da Capoeira, incluindo as variações de estilos e utilização pelos conhecidos malandros, idealizando uma técnica singular para praticá-la e ensiná-la com características esportivas.

Sinhozinho teve duas gerações de alunos de Capoeira. Uma durante a primeira metade da década de 1930 e outra logo após o término da Segunda Guerra Mundial, principalmente a partir de 1946. Segundo Ruy castro, formou três gerações de atletas: "os mais velhos falam dele até hoje como uma lenda em Ipanema" (2002, p. 350 a 352).

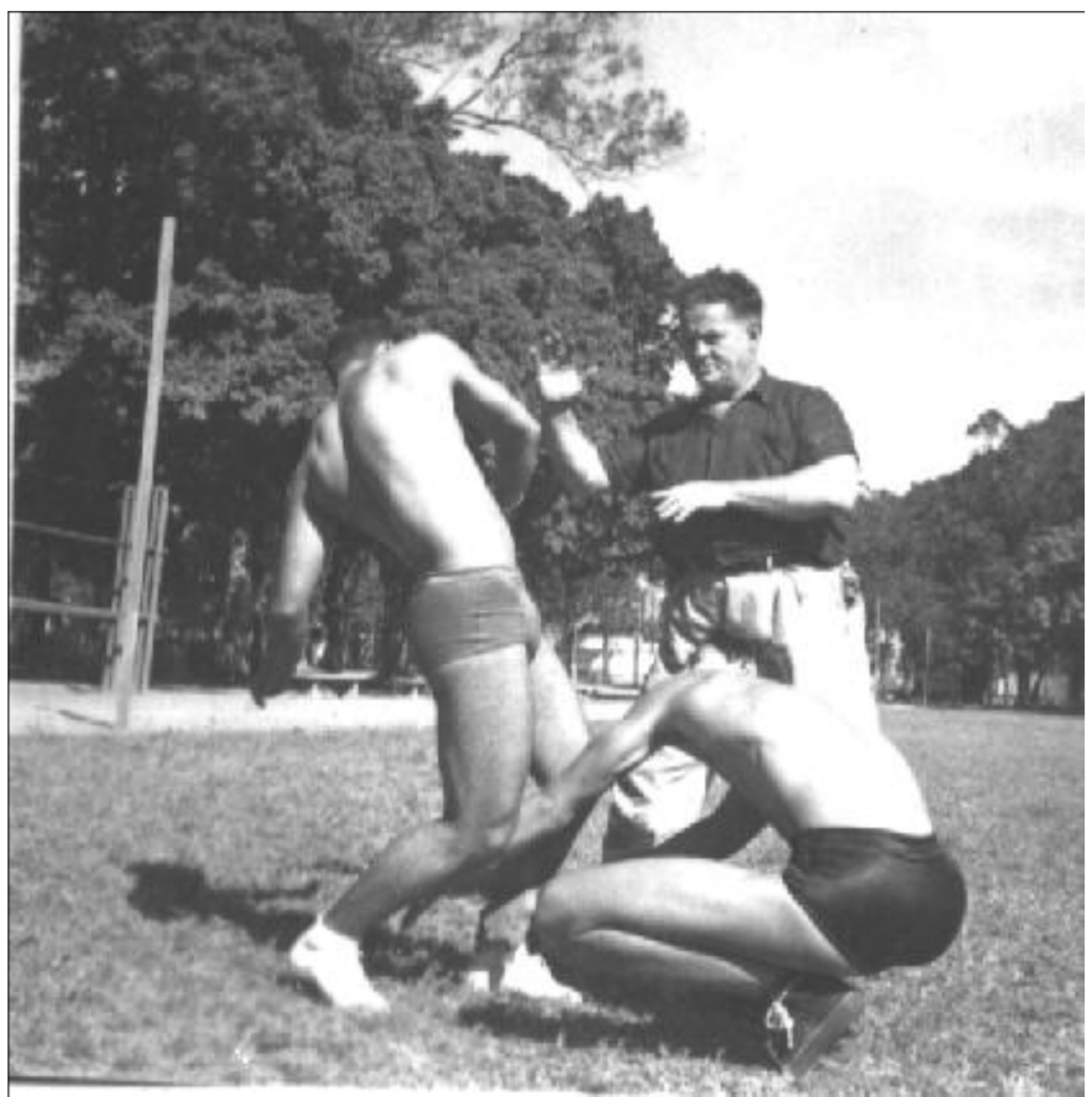

Figura 3. Sinhozinho explicando uma técnica a Quim e Rudolf Hermanny Rio de Janeiro, 1951. Fonte: LOPES, 2002, p. 140. 


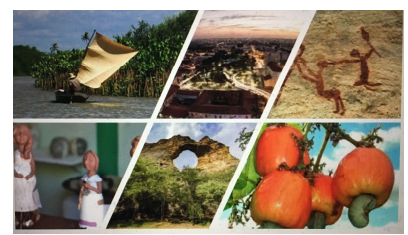

ISBN: 2675-1496 DOI: https://doi.org/10.26694/caedu.v1i2.9911

Isto faz sentido, pois em 1935 entrou para a Polícia de Vigilância da Cidade do Rio de Janeiro, espécie de Guarda Municipal da época, onde foi inspetor, policial e mestre de educação física, atuando como treinador na instituição. É bem provável que Sinhô tenha ensinado a Capoeira na Polícia de Vigilância da Cidade do Rio de Janeiro, não interrompendo sua prática e ensino, sendo esta fase sua segunda geração de atletas. Entretanto, parece que ele deixou de atuar nos clubes esportivos cariocas. Isto deve ter ocorrido não só por sua estabilidade do novo trabalho, mas também, por já estar na casa dos quarenta anos de idade, o que pesava em uma época em que o treinador de esportes também era visto necessariamente como um atleta.

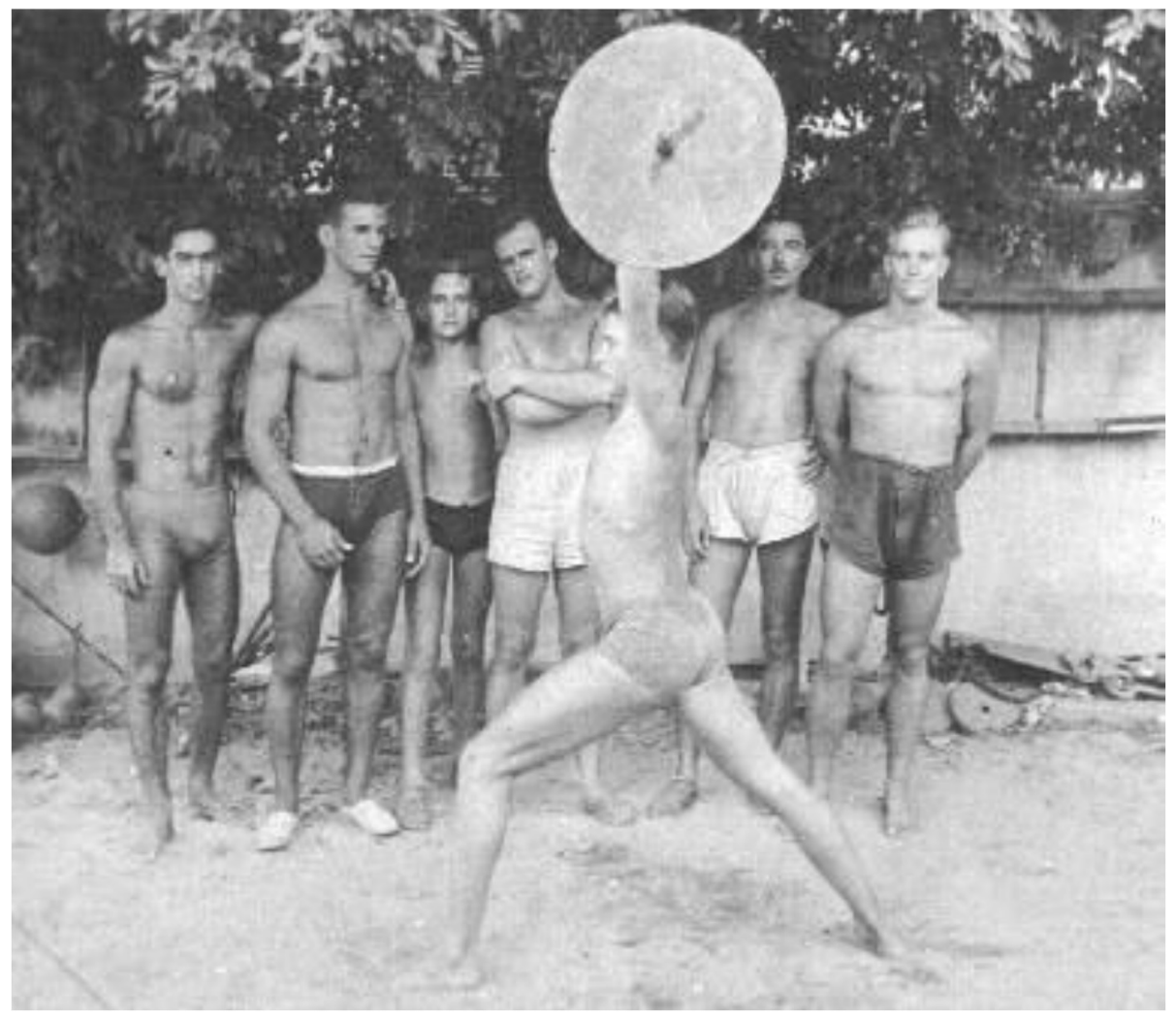

Figura 4. Levantando peso, ainda na adolescência, está Tom Jobim, um dos maiores compositores e representantes da música brasileira. Observam: Carlos Madeira, Paulo Amaral, Rudolf Hermanny, Haroldo C. Silva, Flávio Vitamina e Bube Assinger. Todos alunos de Sinhozinho - Ipanema, Rio de Janeiro, 1945. Fonte: LOPES, 2002, p. 204. 


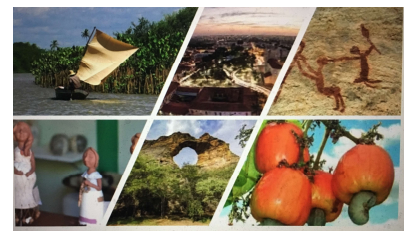

ISBN: 2675-1496 DOI: https://doi.org/10.26694/caedu.v1i2.9911

Agenor Moreira Sampaio também foi um dos primeiros que compuseram a Polícia Especial, e aposentou-se, pouco antes de falecer em 1962, como Oficial de Vigilância. Sinhô observou o início, mas não a intensa institucionalização da Capoeira. Também não vislumbrou a expansão mundial, a abertura na mídia e a quebra de preconceitos que atingiam o jogo-luta. Teve um envelhecer modesto, mas com muitas amizades de seus pupilos.

Ao mesmo tempo em que deixava de ensinar a Capoeira, até o momento de sua morte, durante o início da segunda metade do século XX, a cidade do Rio de Janeiro começava a receber na década de 1950 a influência da Capoeira baiana, por meio de baianos radicados no Rio, como: Joel Lourenço do Espírito Santo, Artur Emídio de Oliveira, e os Mestres Paraná e Mucungê (LUSSAC, 2004).

A primeira geração da Capoeira de Sinhô tem como expoente o aluno Andre Jansen, pupilo de Sinhô, campeão carioca de capoeiragem, goleiro do Botafogo. Fez uma luta principal em 30 de outubro de 1935, no Parque Boa Vista, em Salvador, no Estado da Bahia, contra Ricardo Nibbon, aluno de George Gracie, campeão carioca de jiu-jitsu e de catch-as-catch can na Bahia.

Já a segunda geração da Capoeira de Sinhô é bem mais numerosa e proporcionou um maior impacto social. Compuseram principalmente esta geração: Luiz Pereira Aguiar (campeão brasileiro de capoeira e de levantamento de peso), também conhecido por Ciranda ou Cirandinha, que, em 1946, tornou-se o primeiro aluno da segunda geração da Capoeira de Sinhô; Rudolf de Otero Hermanny (professor de educação física, capoeira e lutador, campeão brasileiro e Pan-Americano, por equipe, de Judô, no México, em 1960. Foi professor da UFRJ e preparador físico da Seleção Brasileira de Futebol na Copa do Mundo de Futebol de 1966), também conhecido por Urso, iniciou seus treinos com Sinhô em 1948; Joaquim Gomes, também conhecido por Quim ou Kim, em 1950 começou a aprender os golpes da luta brasileira com Sinhozinho. Em 1951, Carlos Albero Pettezzoni Salgado, o Belisquete (apresentou a Capoeira, em 1954, nos EUA, no New Orleans 


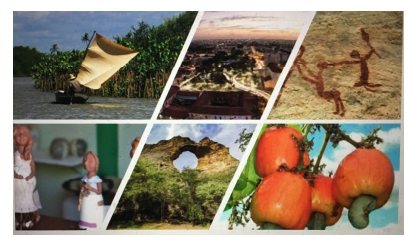

ISBN: 2675-1496 DOI: https://doi.org/10.26694/caedu.v1i2.9911

Athletic Club e em TVs americanas. Pode ser considerado o primeiro brasileiro a ensinar a Capoeira de modo esportivo no exterior), e Carlos Alberto Monteiro Rego, o popular Copacabana. Pouco depois, Roberto William, Professor de educação física da Escola Nacional de Educação Física, também iniciava seus treinos de Capoeira com Sinhozinho.

Sinhozinho realizava uma seleção criteriosa de alunos-atletas. Até por que, ensinava gratuitamente. Treinavam em média três vezes por semana durante aproximadamente por, no mínimo, vinte minutos, inclusive em tatame, evitando ferimentos e possibilitando a inclusão e o treino de outros tipos de técnicas na Capoeira. A indumentária, caracteristicamente esportiva, era composta por tênis e short. Também realizavam dieta apropriada para um atleta, apesar de alguns também gostarem da boêmia.

Sinhozinho idealizou muitos utensílios e aparelhos para o treino das modalidades esportivas que ensinava ${ }^{4}$. Para a Capoeira, por exemplo, inventou um tênis, um tipo de sapato diferente para o treino, acolchoado e macio, semelhante à luva de boxe. Preconizava não menos de 15 e não mais de 40 anos para a prática da Capoeira, pois acreditava necessitar de exercícios especiais preparatórios para a modalidade. É possível notar uma grande característica diferencial do ensino da Capoeira por Sinhozinho: ele também atuou no seio da família da alta sociedade carioca.

\footnotetext{
${ }^{4}$ Um resgate mais detalhado deste aspecto é algo interessante para ser revisto e aproveitado pelos mestres da Capoeira atual.
} 


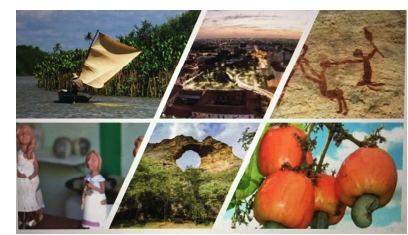

ISBN: 2675-1496 DOI: https://doi.org/10.26694/caedu.v1i2.9911

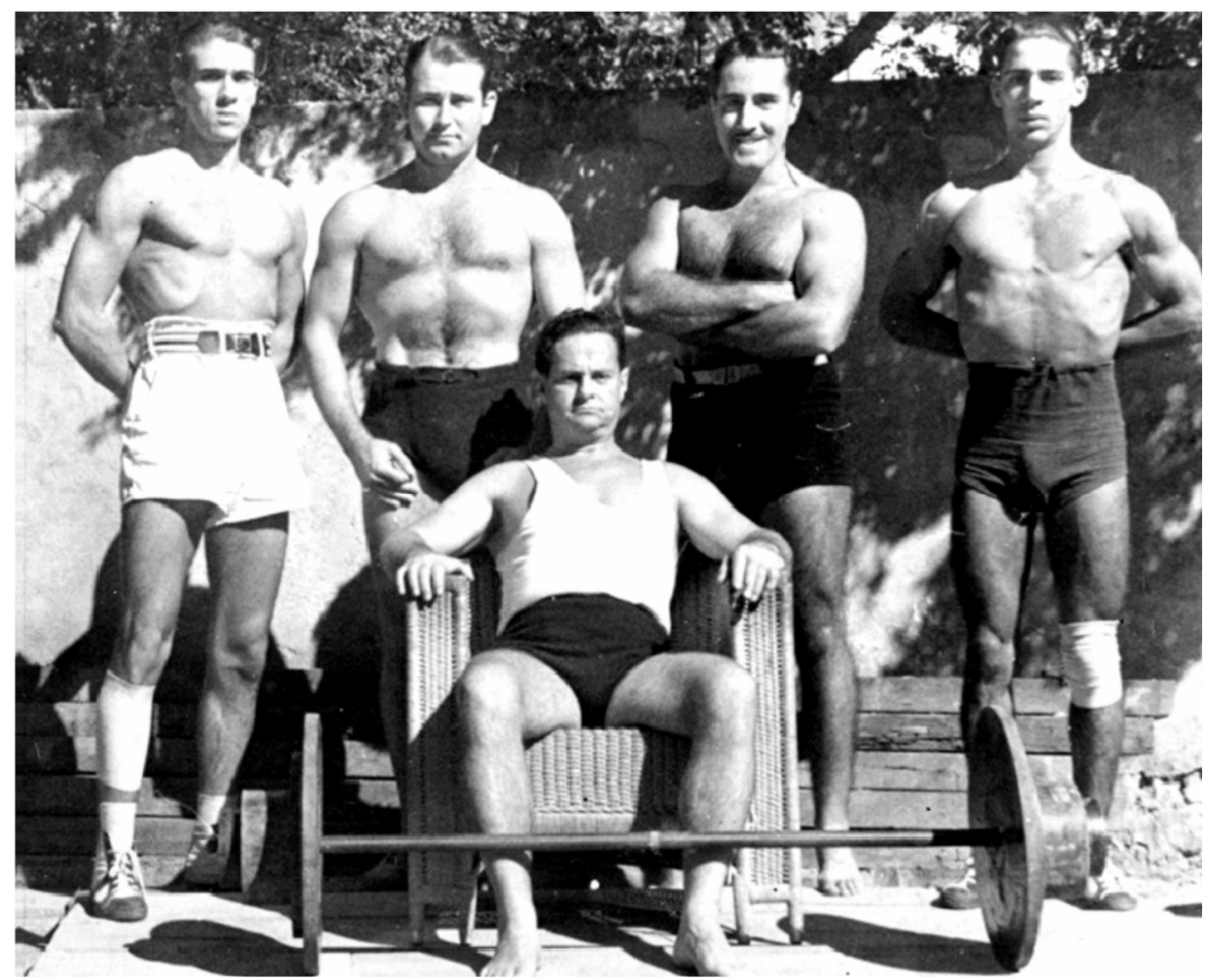

Figura 5. Sinhozinho sentado e Prof. Paulo Azeredo, o

primeiro à esquerda, em 1940. Fonte: LOPES, 2002, p. 151.

Também é possível apontar outros principais alunos de Capoeira de Sinhozinho, dentre eles: os irmãos Marinho, Alberto Silva, Eurico Fernandes; Bruno Hermanny (bicampeão mundial da caça submarina, irmão de Rudolf Hermanny); Paulo Amaral (preparador físico da seleção brasileira de futebol na década de 1970); João Fontes (advogado e ex-presidente da AMA-Leblon); Silvio M. Padilha (descobriu e iniciou o sexto maior corredor do mundo na prova com obstáculos. Foi Presidente do Comitê Olímpico Brasileiro); Paulo Azeredo (considerado o atleta mais completo de seu tempo, vencedor em mais de vinte e oito modalidades); Antonio Carlos Jobim (apesar de Sinhô o considerar um atleta nato, foi um aluno sem destaque esportivo, pois tinha que poupar as mãos para o piano. Sofreu um acidente esportivo realizando uma parada de mãos na Capoeira, afastando-o dos treinos. Apresentou Rudolf Hermanny ao Sinhô. Foi um dos 


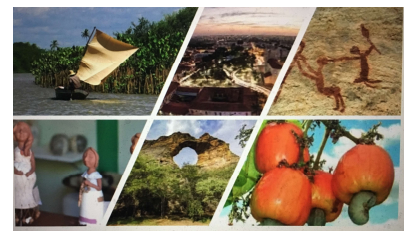

ISBN: 2675-1496 DOI: https://doi.org/10.26694/caedu.v1i2.9911

maiores músicos e compositores brasileiros); Mário Pedregulho; Sergio Luís Salgado Pettezzoni de Almeida (assessor jurídico especialista do extinto $\mathrm{BNH}$, irmão do Carlos Albero Pettezzoni Salgado, o Belisquete); Carlos Cocada; Hugo Mello; Neyder Alves; Sylvio Redinger, também conhecido por Redi (foi um exímio e famoso cartunista carioca); e André Luiz Lacé Lopes (um dos maiores pesquisadores da Capoeira, especialmente da Capoeira de Sinhô). ${ }^{5}$

\section{Sinhozinho: aspectos sociais}

Apesar dos preceitos esportivos, Agenor Moreira Sampaio, tinha uma parcela de sua vida na boemia carioca. Fumava e bebia. Gostava de beber chope com seus alunos no bar Jangadeiro. Tinha um temperamento violento, mas ao mesmo tempo era generoso, amigável e voluntário. Detinha certo prestígio social no esporte e na prática e ensino de outras modalidades esportivas, com o qual propiciou a facilitação do ensino e da inserção da Capoeira no meio esportivo da sociedade carioca.

Ensinou diversas modalidades além da Capoeira original ${ }^{6}$ do Rio de Janeiro, as quais se podem citar: luta romana, greco-romana, lutas e combates de vale-tudo, boxe, boxe francês ou savate, ginástica, ginástica em aparelhos, pesos e alteres, corrida, remo, atletismo, futebol, queda-de-braço, entre outras. Também atuou como massagista.

\footnotetext{
${ }^{5}$ Outros alunos, não menos importantes, compuseram a lista de atletas treinados por Agenor Moreira Sampaio em diversas modalidades: Tromposki; Luiz Felipe Mendonça, o "carregador de piano"; Reinaldo Lima, também conhecido por Broa, (campão de luta romana); Paulo Paiva (campão de luta romana); Mário Diniz (diretor-redator do A.A.A.S.); Jorge Bath "Banheira" (diretor-presidente do A.A.A.S.); Eloy Dutra (foi deputado estadual do antigo Estado da Guanabara); Paulo Cunha da Silva; Floriano Codeço; José da Silva Seabra; Dr. Antero Wanderley; Dr. Rodrigo Flávio Magalhães; Telmo Maria; Carlos Madeira; Darke de Mattos; Comandante Max; Paulo Lefevre; Bube Assinger; Wanderley Fernandes, o Paraquedas; José Alves, o Pernambuco; Carlos Pimentel; Lucas Cunha; Haroldo Cunha; Manoel Simões Lopes; Flávio Maranhão; Délio Jardim de Mattos (Brigadeiro da Aeronáutica); entre tantos outros.

${ }^{6}$ Quando afirmo capoeira carioca, é por seu método singular ser baseado exclusivamente na Capoeira do Rio de Janeiro. É necessário apontar que a Capoeira de Sinhozinho se diferenciava muito da Capoeira praticada e ensinada pelas classes populares, fosse por trabalhadores, fosse por malandros, por, inclusive, não aproveitar os elementos lúdicos presentes nos btuques cariocas.
} 


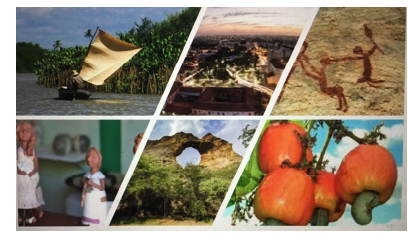

ISBN: 2675-1496 DOI: https://doi.org/10.26694/caedu.v1i2.9911

Existem interessantes "causos", curiosidades e dicas de Agenor Moreira Sampaio e de seus alunos, como por exemplo, o soco no jegue atropelado no asfalto quente do arpoador, também conhecido pelos socos no burro da carroça, a disputa da queda-debraço com um estivador gigante de Santos em um cabaré da Lapa, e o caso da fumaça no ônibus. Também, em 1917, conseguiu ficar entre 40 e 45 minutos em pé em um duelo contra o exímio e muito mais forte e pesado lutador de greco-romana João Baldi, episódio o qual não houve dinheiro para cobrir as apostas. Ainda em m 1924, houve o caso da roda da Haddock Lobo em pleno estado de sítio. Infelizmente, só é possível pontuar e não transcrever aqui tais episódios e "causos", devido ao limite de tamanho deste trabalho. Entretanto os aspectos relacionados como os "causos", curiosidades e dicas de Sinhô e alunos, são relevantes, pois, propiciam construir, em parte, um comportamento sociocultural, que acaba por também alimentar o imaginário sobre tais sujeitos.

Sinhozinho utilizava uma vara de marmelo e, em outras ocasiões, também uma bengala durante os seus ensinamentos e treinos de alunos. A utilização da vara de marmelo e da bengala em seu ensino evidencia a didática e o método de ensino da época, assim como a cultura de alguns instrutores de artes marciais, que podem ser vistas até hoje.

Sinhô acreditava na força do exemplo para ensinar. Ensinava que, em uma briga, se deveria sorrir e, no caso de uma briga contra um grupo, preconizava seguir a tática de bater primeiro. Sua relação com as forças de segurança oscilavam entre, o próprio trabalho, brigas e amizade, a exemplo de seus pupilos: Cirandinha, Mário Pedregulho e Quim.

No primeiro quadrimestre de 1949, alguns alunos de Mestre Bimba, mestre baiano que criou e ensinava a Capoeira Regional, apresentaram-se em ringues de luta no Estádio do Pacaembu, nos meses de fevereiro e março, na cidade de São Paulo e, logo após, sem mais o Mestre Bimba acompanhando-os, vieram para a cidade do Rio de Janeiro para se apresentar. Durante tal evento, foram desafiados por lutadores de outras modalidades e também por Sinhozinho, por meio do jornal Gazeta Esportiva, colocando seus discípulos 


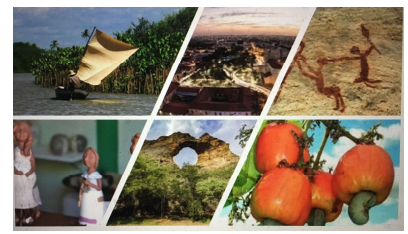

ISBN: 2675-1496 DOI: https://doi.org/10.26694/caedu.v1i2.9911

da Capoeira Utilitária, Cirandinha e Rudolf Hermanny, nos ringues e vencendo facilmente os capoeiristas baianos no Estádio Carioca, na Avenida Passos, Centro do Rio (LOPES, 2002, p. 188 a 192).

Pelos dados colhidos, observou-se que Sinhozinho iniciou cedo a sua vida esportiva ainda em Santos, no Estado de São Paulo. Foi um atleta vencedor em várias modalidades, lutador, massagista e um grande treinador e instrutor de educação física, contribuindo muito no ensino dos esportes. Aprimorou-se lendo tratados de cultura física que mandava vir da França e tinha influência e conhecimento na Escola Nacional de Educação Física.

Formou vários campeões em diversos esportes, sendo um dos pioneiros do esporte no Rio de Janeiro no início do século XX, tendo trabalhado em inúmeros clubes da cidade até, no mínimo, em 1936, inclusive sendo co-fundador de alguns. Obteve, portanto, particular importância no cenário da vida social esportiva da cidade do Rio de Janeiro no Século XX, dos anos 10 aos 50.

Logo que chegou ao Rio morou no Morro de Santo Antônio, local próximo à Lapa, que abrigava "vadios, ratoneiros, turbulento e facínoras", mas também, coexistindo no mesmo espaço, "homens trabalhadores, na sua maioria estivadores e marítimos" (NORONHA, 2003, p. 62 e 63). Deste modo, é possível inferir, observando a reportagem de 23 de setembro de 1951, do jornal carioca Correio da Manhã, que a probabilidade de Sinhozinho ter aprendido a Capoeira carioca nesta localidade é muito grande.

No Morro de Santo Antônio também funcionou um local de tortura e quartel da Polícia Especial, que ficava pouco atrás do Convento histórico. Este pode ser um detalhe importante a ser analisado futuramente, devido Sinhozinho ter trabalhado na Polícia Especial desde a sua criação. No entanto, não há nada que ligue Sinhozinho à prática de tortura ou de ter trabalhado naquele local. Destarte, percebo que ainda é necessário maiores pesquisas sobre a vida e atuação social e esportiva de Sinhô durante o período do Estado Novo. 


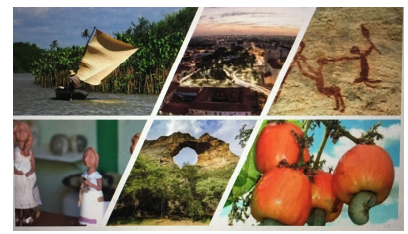

ISBN: 2675-1496 DOI: https://doi.org/10.26694/caedu.v1i2.9911

Boêmio, fumava e bebia, de personalidade forte e marcante e com um temperamento violento, ao mesmo tempo era generoso, amigável, voluntário, ensinou a inúmeras pessoas, de diferentes classes sociais, destacando alunos da elite carioca, principalmente do bairro de Ipanema. Também atuou nas Polícias de Vigilância e Especial, aposentando-se em 1959.

Ensinou gratuitamente a Capoeira carioca, não conseguindo comercializar seu trabalho com esta modalidade. Nota-se claramente a grande singularidade em sua prática e respectivas contribuições no ensino, resgate e difusão da Capoeira carioca. Encarava e difundia a Capoeira como Luta Brasileira, Defesa Pessoal, Gymnastica Nacional, ressaltando os seus aspectos de luta, esporte e ginástica. Ensinou no centro (1930-31), mas obteve relativo sucesso - por determinados fatores - no quintal de sua casa, e em um terrenos baldios no bairro de Ipanema, que transformava em locais de treino. Portanto, sua prática requeria baixíssimos custos, em terrenos baldios, com aparelhos inventados por ele próprio, e por ensinar gratuitamente a seus alunos. Também não utilizava instrumentos musicais e elementos lúdicos do jogo, uma das características de sua Capoeira. Portanto, o simulacro e treino de luta era muito mais objetivo que na Capoeira popular carioca ou baiana. ${ }^{7}$

Abriu uma academia, também a primeira de Ipanema, suprindo uma carência do local. A academia, "Clube do Sinhozinho", mudou para vários outros lugares. O real sucesso com a sua Capoeira só foi obtido com sua segunda geração de alunos de Capoeira, a partir de 1946 em diante. Mantinha rigorosos critérios na seleção de alunos-atletas. Muitos destes, futuramente, seriam destaques na sociedade carioca. Sugeria uma faixa etária apropriada para a prática, seus alunos treinavam com uma rotina, dieta e vestes

\footnotetext{
${ }^{7}$ É necessário delimitar esta objetividade bélica, visto levar em consideração cada contexto cultural de ocorrência da expressão Capoeira, com seus respectivos sujeitos e ambientes sócios históricos envolvidos, pois qualquer arte marcial não pode ser somente percebida como um conjunto de técnicas. Há diversos elementos abstratos de conhecimentos que perfazem os arcabouços e repertório de cada expressão cultural. No caso, afirmo que tal superioridade bélica do treinamento ocorre pelos resultados de lutas dos alunos de Sinhozinho nos ringues. Marinho (1945, p. 30) também contribui com este raciocínio ao "testar" um capoeira carioca em luta, em 1938.
} 


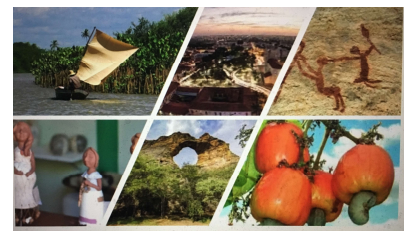

ISBN: 2675-1496 DOI: https://doi.org/10.26694/caedu.v1i2.9911

apropriadas, e utilizavam equipamentos variados, muitos deles inventados por Sinhô, e apropriados para as modalidades que ensinava. Sinhozinho tinha a intenção de difundir a Capoeira e deve ser reconhecido pelo notável esforço em não deixar a capoeiragem carioca morrer.

Tal reconhecimento, inclusive por ser um grande treinador e formador de atletas, se deu por uma homenagem ao ter uma rua nominada com seu nome - Rua Agenor Sampaio - na Ilha do Governador, nas proximidades do Jardim Carioca, Guarabu, Cocotá.

As três reportagens sobre Sinhozinho, todas publicadas em jornais do Rio de Janeiro, são significativas, diferindo a de 01 de setembro de 1931, Clube Nacional de Ginástica: uma grande promessa, do jornal Diário de Notícias, pois aponta para o preconceito ainda existente sobre a prática, abordando sua versão esportiva como violenta e de difícil regulamentação. Possivelmente estas características fizeram muitos desistirem da prática esportiva da modalidade, sua baixa aceitação e, consequentemente, sua pouca difusão.

Já as reportagens de 07 de julho de 1951, O Destino da Capoeira, publicada no $O$ Globo Esportivo, e a Trabalha-se no Brasil pela sobrevivência da capoeira, publicada em 23 de setembro de 1951, pelo Correio da Manhã, apontam para uma Capoeira que tenta se soerguer e galgar novos rumos por meio de Sinhozinho no Rio de Janeiro. Nestas reportagens, Sinhozinho expressa claramente que considerava a Capoeira como a Ginástica Nacional.

As informações de Ruy Castro (2002) e Mário Peixoto (1999), por muitas vezes se contradizem quando comparadas e sobrepostas. Observa-se também informações inexatas na obra de Waldeloir Rego (1968), como, por exemplo, a de que Sinhozinho era baiano. Mas as mesmas não desmerecem o restante de sua obra.

Informações de que Sinhô teria morado em São Cristóvão, onde realizava os treinos da Polícia de Vigilância, e ainda em Copacabana, onde tinha aluno(s) foram encontradas, mas após a análise e a construção de uma narrativa lógica, há uma 


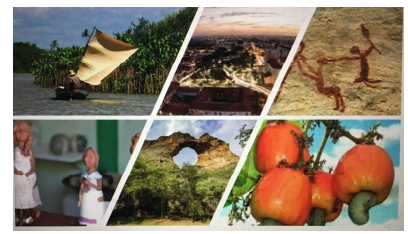

ISBN: 2675-1496 DOI: https://doi.org/10.26694/caedu.v1i2.9911

probabilidade muito baixa da veracidade de tais informações. Pode-se também, baseados nestas informações, especular que Sinhô poderia ter ensinado em tais bairros.

É necessário ainda, analisar a informação oferecida por Inezil Penna Marinho (MARINHO, 1945, p. 30), quando nos diz que Sinhô mantinha uma academia de Capoeira em Ipanema, na época em que o autor escreveu a sua monografia, apresentada em 1944 e publicada em 1945. Se tal monografia foi apresentada em 1944, podemos acreditar que neste ano ou mesmo antes, Sinhozinho ensinava capoeira, o que contradiz as informações de que a segunda geração de capoeira de Sinhô teria o seu início em 1946, com Cirandinha. A figura 3, uma foto de 1945 do acervo de André Lacé também corrobora para isto.

Logo: 1944 - 8 anos = 1936 ou menos: ou seja: a informação de que a existência da primeira turma - geração - de Capoeira de Sinhô, com 5 alunos, se deu entre 1930-35, não procede com os dados levantados com base nas informações acima. Pois, baseados nesta, por volta de 1936, Sinhozinho ensinava Capoeira, assim como ainda trabalhava no Fluminense F.C., o último clube constatado na pesquisa em que Sinhô trabalhou.

Inezil ainda comenta: "visitamos a academia de Sinhozinho, de quem fomos aluno há uns oito anos" (MARINHO, 1945, p. 30), assinalando a existência da academia de Sinhozinho in locus pelo autor. E ainda: "fomos", no plural, nos faz poder concluir duas hipóteses: ou ele usou o verbo no plural, por ser comum em alguns trabalhos acadêmicos, ou havia outros que teriam sido alunos de Sinhô junto com Inezil. O fato de a palavra "aluno" estar no singular, propicia uma maior lacuna de dúvidas acerca destas especulações interpretativas.

Apoiando-se nos argumentos acima, pode-se levantar a hipótese perfeitamente plausível de que não houve interrupção no ensino da Capoeira por Sinhozinho, e sim, uma não continuidade por parte de seus alunos, o que merece outra apreciação e reflexão. Talvez esta interrupção possa ter sido durante o período do Estado Novo, 1937-1945, ou da Segunda Grande Guerra 1939-1945, até por que, não foi verificada a atuação de Sinhozinho em outro clube após o citado acima. 


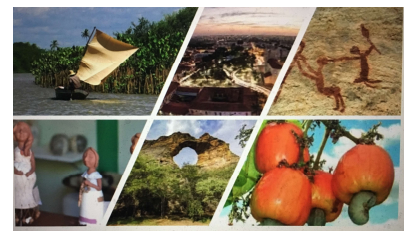

ISBN: 2675-1496 DOI: https://doi.org/10.26694/caedu.v1i2.9911

Do mesmo modo, também é possível que o período da dita interrupção do ensino de Capoeira por parte de Sinhô não tivesse ocorrido, por o mesmo ter ensinado tal prática na Polícia de Vigilância e na Polícia Especial. Neste caso, maiores estudos são necessários para elucidar a relação de Sinhô com os órgãos de repressão, seja como agente, seja como cidadão comum, principalmente, no período do Estado Novo.

Outra reflexão seria sobre a hipótese de que o prestígio social no esporte, a prática e ensino de outras modalidades esportivas e o fato de Sinhozinho ser da Polícia Especial propiciaram e facilitaram, em termos de aceitação social, o ensino da Capoeira por Sinhozinho. Também podemos inferir a hipótese de que a publicação do livro de Annibal Burlamaqui, o Zuma, em 1928, teria idealizado e motivado Sinhozinho a resgatar, ensinar e difundir a Capoeira, entendendo-a como a Luta Brasileira, uma Defesa Pessoal, com aspectos de luta, esporte e ginástica concomitantemente, que deveria ser compreendida como a Gymnastica Nacional.

\section{Considerações finais}

Investigar, analisar e discutir os aspectos mais relevantes da vida esportiva e social de Agenor Moreira Sampaio, e suas contribuições para a Capoeira e para o esporte, torna relevante este trabalho por serem escassas as reflexões e pesquisas acadêmicas a respeito deste sujeito e de suas respectivas contribuições.

Concluo, portanto, que é inegável a enorme contribuição de Agenor Moreira Sampaio, o Sinhozinho, para o esporte no Rio de Janeiro e no Brasil. Talvez, sua maior contribuição seja a singular e criativa prática e ensino da Capoeira, de origem carioca, que preconizava e ajudou a resgatar, desenvolver e difundir, demonstrando o imenso potencial de luta da Capoeira original carioca.

A vida e obra de Agenor Moreira Sampaio ainda é um terreno onde muito há de ser pesquisado, tornando-o um campo fértil ao desbravamento por novos olhares e interpretações, e também suas respectivas imbricações com outros fatores, como por 


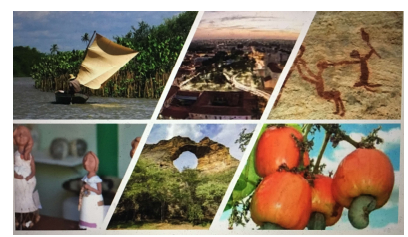

ISBN: 2675-1496 DOI: https://doi.org/10.26694/caedu.v1i2.9911

exemplo: a relação de Sinhozinho entre os órgãos de repressão e a sua atuação com o ensino da Capoeira; o suposto período em que Sinhô não teria ensinado a Capoeira (e outras modalidades); a influência da Capoeira do Rio de Janeiro (Capital Federal), da Capoeira de Sinhô e das obras e reportagens publicadas neste período, sobre a Capoeira em outros estados do Brasil, principalmente na Bahia, em especial sobre as influências acerca da elaboração da Capoeira Regional.

Por fim, ao chegar nestas considerações finais, permitido recomendar as seguintes sugestões mais específicas: seria interessante que, por meio de um mapa geográfico de Ipanema, do ano aproximado de 1950, fosse mapeado os locais onde Sinhozinho ensinou a Capoeira e após, analisar tal mapeamento contrastando as informações de Ruy Castro (2002) e Mário Peixoto (1999). Sugiro, portanto, que sejam realizadas mais pesquisas de campo. Entrevistas com Rudolf Hermanny, outros remanescentes alunos de Sinhô, e pesquisadores conhecedores sobre o assunto como, por exemplo, André Lacé, por mais que estes já tenham sido entrevistados, podem ainda preencher lacunas não respondidas ou com dados conflitantes. Outra recomendação para futuros estudos, a qual julgo apropriada, é que seja pesquisada a origem da denominação nominal da Capoeira de Sinhozinho, como: Capoeira Utilitária.

Destarte, este trabalho ilumina parcialmente questões que envolvem o assunto ao analisar e confrontar as fontes e documentos, discutindo os processos de socialização envolvidos e as trajetórias de formação, as memórias, narrativas e experiências deste personagem da vida carioca. Deste modo, é possível inferir que esta pesquisa contribui com importantes subsídios sobre o tema e para a reconstrução do mosaico sobre a história da Capoeira.

\section{Referências}

BURLAMAQUI, Annibal (Zuma). Gymnastica Nacional (Capoeiragem) - methodizada e regrada. Rio de Janeiro: Editora, 1928. 


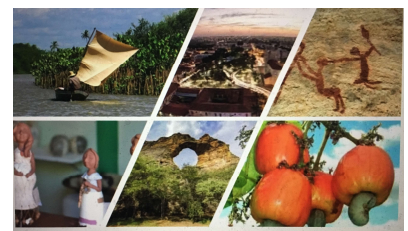

ISBN: 2675-1496 DOI: https://doi.org/10.26694/caedu.v1i2.9911

CASTRO, Ruy. Ela é Carioca: uma enciclopédia de Ipanema. Rio de Janeiro: Companhia das Letras, 2002.

DUTRA, Eloy. Boletim da A.A.A.S. nº 1. jun. 1946.

FARIA JÚNIOR, Alfredo Gomes de. Pesquisa e Produção do conhecimento em Educação Física. SBDEF. p. 16-19, Editora Livro Técnico, 1991.

HERMANNY, Rudolf. Rudolf Hermanny. Luiz Carlos Lisboa, organizador. Rio de Janeiro: Ediouro: Ed. Rio, 2003.

LAKATOS, Eva Maria; MARCONI, Marina de Andrade. Fundamentos de metodologia científica. $6^{\text {a }}$ ed. $-3^{\text {a }}$ reimpr. São Paulo: Atlas, 2006.

LIMA e SILVA, Waldemar de. Colaborador: FARIA, Alberto Latorre de. Defesa Pessoal (Método eclético - Box - Jiu-jitsu - Capoeiragem - Luta livre) Contendo os regulamentos de Box internacional, Jiu-jitsu, Luta romana, Box francês e Capoeiragem. Ilustrado com 201 gravuras. Rio de Janeiro: Editor Borsoi, 1951.

LOPES, André Luiz Lacé. A Capoeiragem no Rio de Janeiro, primeiro ensaio Sinhozinho e Rudolf Hermanny. Rio de Janeiro. Editora Europa, 2002.

- A Volta do Mundo da Capoeira. $1^{\text {a }}$ edição, Rio de Janeiro: Coreográfica Editora e Gráfica, 1999.

LUSSAC, Ricardo Martins Porto (Mestre Teco). Desenvolvimento psicomotor fundamentado na prática da capoeira e baseado na experiência e vivência de um mestre da capoeiragem graduado em educação física. Rio de Janeiro: Universidade Cândido Mendes, Projeto A vez do Mestre (Monografia de Pós-Graduação Lato Sensu: Especialização em Psicomotricidade), 2004.

MARINHO, Inezil Penna. Subsídios para o estudo da metodologia do treinamento da capoeiragem. Rio de Janeiro: Imprensa Nacional, 1945.

MATTOS, Mauro Gomes de; ROSSETO JÚNIOR, José; BLECHER, Shelly. Teoria e prática da metodologia da pesquisa em educação física: construindo seu trabalho acadêmico: monografia, artigo científico e projeto de ação. São Paulo: Phorte, 2004.

NORONHA, Luiz. Malandros: notícias de um submundo distante. Rio de Janeiro: RELUME Dumará: Prefeitura - Coleção Arenas do Rio - 12, 2003.

PEIXOTO, Mário. Ipanema de A a Z. Rio de Janeiro: Aacohen, 1999. 


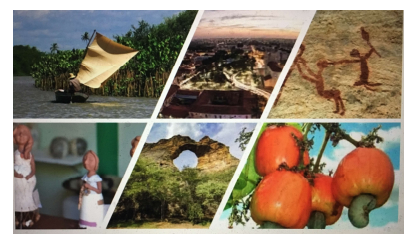

ISBN: 2675-1496 DOI: https://doi.org/10.26694/caedu.v1i2.9911

PETTEZONNI, Sergio. Rio para não chorar. Rio de Janeiro: Catau, 1995.

PIRES, Antonio Liberac Cardoso Simões. Culturas Circulares: a Formação Histórica da Capoeira Contemporânea no Rio de Janeiro. Curitiba: Editora Progressiva, 2010.

REA, L. M; PARKER, R. A. A metodologia da pesquisa: do planejamento à execução. São Paulo, Pioneira, 2000.

REGO, Waldeloir. Capoeira Angola: ensaio sócio-etnográfico. 1. ed., Salvador: Itapuã, Coleção Baiana, 1968.

SILVA, Raul Mendes; CACHAPUZ, Paulo Brandi; LAMARÃO, Sérgio (org.). Getúlio Vargas e seu tempo. Rio de Janeiro: BNDES, 2004. 